\title{
Avaliação de modelo probabilístico de propagação de incêndios florestais utilizando autômatos celulares aplicado a pequenas áreas
}

\author{
Evaluation of the probabilistic model of fire propagation using cellular automata \\ applied to small areas
}

\author{
Everton dos Santos ${ }^{\mathrm{I}}$, Luiz Felipe Ramos Turci ${ }^{\mathrm{II}}$, Rodolfo Maduro Almeida ${ }^{\mathrm{III}}$
}

\section{Resumo}

O Parque Municipal da Serra de São Domingos, localizado em Poços de Caldas, Minas Gerais, Brasil, apresenta ocorrências de incêndios anuais, que promovem perdas ambientais e socioeconômicas. A utilização de um modelo de propagação de incêndio que possa auxiliar no planejamento do combate, e até na prevenção desses incêndios, seria extremamente benéfico para o município e para Corpo de Bombeiros. Os objetivos deste trabalho são a apresentação dos estudos de incêndios na área e a parametrização e avaliação de um modelo probabilístico de propagação de incêndio, baseado na metodologia dos autômatos celulares, similar a modelos utilizados na região do bioma Cerrado. A caracterização dá-se a partir de utilização de ferramentas de sensoriamento remoto e dados meteorológicos, e a parametrização do modelo utilizou dados de um incêndio com área afetada bem mapeada e ponto de ignição bem conhecido, procedendose o ajuste do modelo aplicando-se o algoritmo meta-heurístico de enxame de vagalumes. A eficácia do modelo foi posteriormente testada com duas ocorrências de incêndio distintas, ambas com área atingida bem mapeada, porém, com ponto de ignição desconhecido. O modelo mostrou-se capaz de representar até $57 \%$ da área real afetada pelo incêndio, e alguns parâmetros foram considerados satisfatórios, como as probabilidades elementares de sustentabilidade e ignição do fogo. Entretanto, os estudos indicam que há a necessidade de maior refinamento nos dados utilizados no modelo, principalmente, dados de umidade e ponto de ignição dos incêndios.

Palavras-chave: Modelagem matemática; Sensoriamento remoto; Incêndios florestais

\begin{abstract}
The Municipal Park of Serra de São Domingos, located in Poços de Caldas, Minas Gerais state, Brazil, presents occurrences of annual fires, which promote environmental and socioeconomic losses. The use of a fire propagation model that could aid in the planning of combat, and even in the prevention of such fires, would be extremely beneficial for the municipality and for the Fire Department. The objectives of this work are the presentation of the fire studies in the area and the parameterization and evaluation of a probabilistic model of fire propagation, based on the cellular automata methodology, like the models used in the Cerrado biome region. The characterization is based on the use of remote sensing tools and meteorological data, and the parameterization of the model used data from a fire with well-defined affected area and well-known ignition point, and the model was adjusted by applying the metaheuristic algorithm of firefly swarm. The efficacy of the model was later tested with two distinct fire occurrences, both with well-struck area hit, but an unknown point of ignition. The model was able to represent up to $57 \%$ of the real area affected by the fire, and some parameters were considered satisfactory, such as the elementary probabilities of sustainability and fire ignition. However, the studies indicate that there is a need for greater refinement in the data used in the model, mainly data on the moisture and ignition point of fires.

Keywords: Mathematical modeling; Remote sensing; Forest fires

\footnotetext{
Engenheiro Ambiental, Mestre em Ciência e Engenharia Ambiental, Programa de Pós-Graduação em Ciência e Engenharia Ambiental, Universidade Federal de Alfenas, Campus Poços de Caldas, Rod. José Aurélio Vilela 11999, Km 533 BR 267, CEP 37715-400, Poços de Caldas (MG), Brasil. evertonds@live.com (ORCID: 0000-0002-6815-1599) Federal de Alfenas, Campus Poços de Caldas, Rod. José Aurélio Vilela 11999, Km 533 BR 267, CEP 37715-400, Poços de Caldas (MG), Brasil. luiz. turci@unifal-mg.edu.br (ORCID: 0000-0001-7516-0963) gmail.com (ORCID: 0000-0003-4564-825X)
}

II Engenheiro Elétrico, Dr., Professor do Núcleo de Matemática, Computação e Modelagem do Instituto de Ciência e Tecnologia, Universidade

III Matemático, Dr., Professor, Universidade Federal do Oeste do Pará, Rua Vera Paz s/n, CEP 68040-255, Santarém(PA), Brasil. rodolfomaduroalmeida@
\end{abstract}




\section{Introdução}

Incêndios florestais causam, frequentemente, diversas perdas ambientais, sociais e econômicas ao redor do mundo: diminuição da fauna e flora local, problemas de saúde relacionados à diminuição na qualidade do ar, gastos com combate e prevenção são alguns dos problemas causados por conta dessas ocorrências. Assim, o entendimento dos fatores que favorecem a ocorrência de incêndios, conciliados a técnicas preventivas, são fundamentais para o manejo e controle desses eventos.

Os modelos matemáticos de propagação de incêndios, compostos por equações teóricas e/ou empíricas, buscam apresentar valores numéricos e representar a evolução temporal-espacial de um incêndio, avaliando parâmetros como: consumo de combustível vegetal; velocidade de propagação do fogo; formato da frente de fogo; risco de ignição; influência das condições meteorológicas (velocidade e direção do vento) e topografia, entre outros. A combinação de diversos modelos, simultaneamente ao uso de recursos computacionais e sistemas de informações geográficas causaram um aumento, considerável, da elaboração de ferramentas para prevenção e combate de incêndios florestais (PASTOR et al., 2003), fazendo com que, a partir da década de 1980, órgãos responsáveis por essas funções, em países como Estados Unidos da América (EUA), Canadá, Portugal, Austrália e outros, passassem a utilizar modelos de propagação de incêndios como ferramenta auxiliar na tomada de decisões e gestão (ANDRE; VIEGAS, 2001).

Os autômatos celulares (CA) são modelos de sistemas físicos, que tratam as variáveis como espaço e tempo de maneira discreta, que têm a capacidade de modelar sistemas dinâmicos complexos, como biologia reprodutiva, sistemas químicos auto-organizáveis, incêndios florestais e outros, a partir de parâmetros simples, e cuja evolução do sistema dependa exclusivamente das interações locais que o constitui (D’AMBROSIO et al., 2006). Um sistema de autômatos celulares é definido como a divisão regular do espaço a ser representado em células, em que cada célula é caracterizada por um estado representativo do estado real do espaço de interesse. A transição de estado das células depende dos estados da própria célula e das células vizinhas, estipulada por uma função de transição e o arranjo da vizinhança das células pode assumir diferentes formas, de acordo com o propósito da modelagem (D’AMBROSIO et al., 2006; LI et al., 2015).

Diversos autores, como: D’Ambrosio et al. (2006); Alexandridis et al. (2008); Almeida; Macau (2011); Achtemeier (2013); Adou et al. (2015); Almeida et al. (2015); Iudin et al. (2015), apresentaram modelos de propagação de incêndio utilizando autômatos celulares, aplicados em diferentes condições de vegetação, relevo e clima, com resultados e aplicabilidade satisfatórios.

Almeida et al. (2015) exploraram um modelo de propagação de fogo, utilizando autômatos celulares, no qual cada célula do sistema possuía uma variável de estado $S$, que dispõe de um conjunto de possíveis estados: $\mathrm{E}, \mathrm{V}, \mathrm{F}$ e O. O estado E representa uma célula vazia, não contendo vegetação para queima; $V$ representa uma célula com vegetação que pode ser consumida pelo fogo; F representa uma célula em que está ocorrendo um incêndio; e O representa uma célula na qual toda a vegetação foi consumida pelo incêndio. A variável de estado $S$ é função de três probabilidades características: D, B e I. As características e parâmetros provenientes da área de interesse determinam as condições de cada uma dessas probabilidades. D está ligada à vegetação disponível no espaço; B está ligada ao processo de combustão, em que, com o passar das iterações do modelo, uma célula passa do estado $\mathrm{F}$ para o estado O; I está ligada ao processo de ignição, em que uma célula com estado $\mathrm{F}$ transmite o fogo para uma célula com estado $\mathrm{V}$.

A probabilidade $D$ relaciona-se à distribuição e densidade da vegetação ao longo do espaço celular, e assume valores no intervalo [0,1], sendo que 1 seria uma célula inteiramente coberta por vegetação, enquanto os valores intermediários consideram qualquer não continuidade da vegetação, como por exemplo, obstáculos (estradas, trilhas, corpos hídricos). A probabilidade B relaciona-se à eficiência do processo de combustão, que depende de três fatores: ignição, combustível e comburente. $B$ assume valores no intervalo [0,1], em que valores mais elevados levam a um consumo acelerado da vegetação disponível para queima. Dessa forma, a sustentabilidade da 
combustão é afetada pelos efeitos atmosféricos, ou seja, a capacidade combustível da vegetação é afetada pela umidade relativa do ar. A probabilidade I, com valores no intervalo $[0,1]$ expõe a capacidade de ignição das células com vegetação no espaço celular, em que valores elevados resultam num aumento da capacidade de propagação do fogo para células vizinhas. A frente de propagação de fogo pode assumir diferentes formas (circular, elíptica ou irregular) de acordo a homogeneidade da vegetação, e efeitos oriundos do relevo e direção do vento que incidem sobre o incêndio (PYNE et al., 1996).

Almeida e Macau (2011) realizaram uma análise qualitativa do modelo, variando os valores para D, B e I, a fim de determinar as fronteiras críticas e padrões de propagação do fogo, determinando também valores para a velocidade adimensional de propagação do fogo, $\mathrm{R}_{\mathrm{a}}$, que indica uma razão entre a velocidade de propagação do incêndio real e a velocidade de propagação do incêndio simulado a cada iteração do modelo - esta última é estimada pela razão entre a distância percorrida pela frente de fogo e o tempo médio de propagação, expresso em iterações do modelo. A Figura 1 apresenta a compilação de suas análises para $D=1$. As análises indicam diferentes faixas de valores para padrões sólidos, dendríticos e de extinção de incêndios; padrão sólido $(S=1)$ ocorre quando os valores de B e I produziram uma frente de fogo definida e sem possibilidade de extinção, enquanto o padrão dendrítico $(0<S<1)$ evidencia-se por uma frente de fogo não uniforme e com possibilidades de extinção; e finalmente, quando $S=0$, não há propagação de incêndio. Além disso, a análise aponta para um limite prático $\mathrm{I}=0,325$.

\section{Figura 1 - Classificação dos padrões de propagação do modelo.}

Figure 1 - Classification of model propagation patterns.

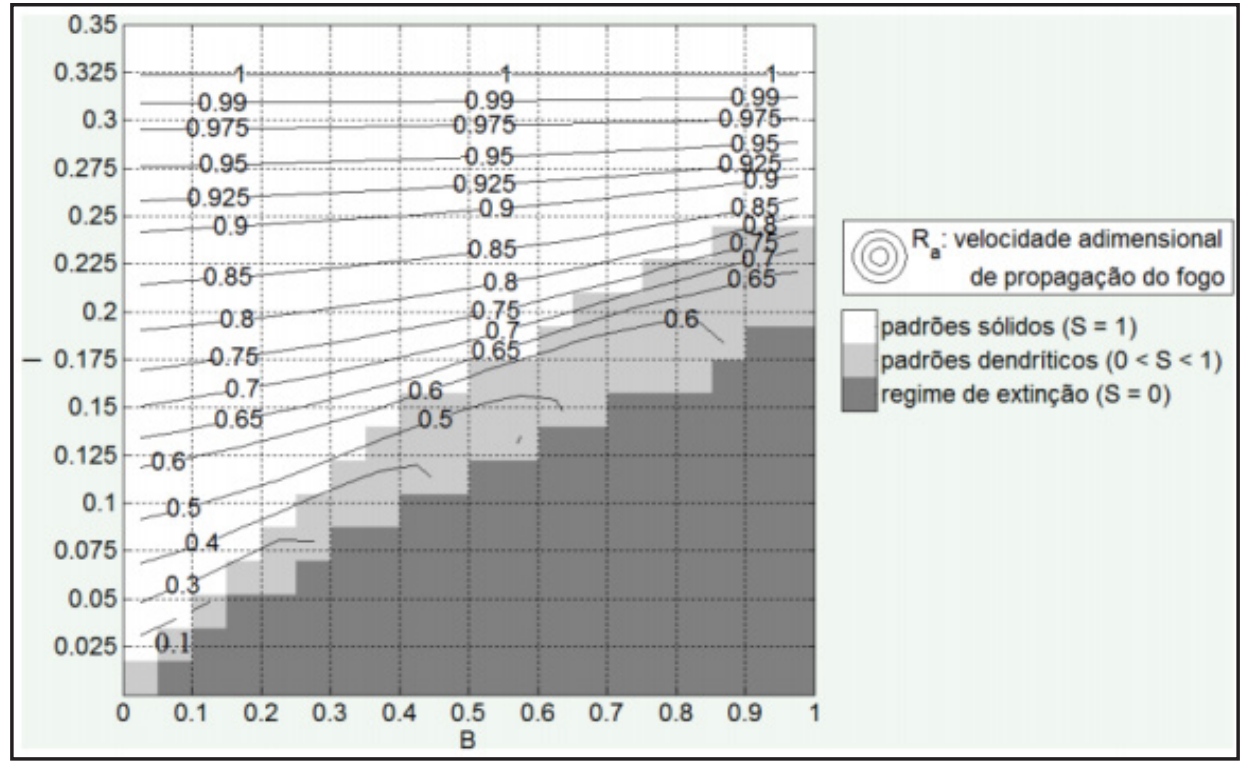

Fonte: Almeida et al. (2015)

Source: Almeida et al. (2015)

Neste trabalho, ajustou-se e analisou-se a aplicação de um modelo probabilístico de propagação de incêndios, desenvolvido por Almeida et al. (2015), que foi, originalmente, ajustado para incêndios de grandes áreas, no bioma Cerrado, com topografia majoritariamente plana, e clima quente e seco. O estudo ocorreu em uma área de pequenas dimensões, bioma misto, topografia montanhosa, e clima variando entre quente e úmido no verão a frio e seco durante o inverno. A área de estudo é uma importante unidade de conservação da mata atlântica, localizada no sul do estado de Minas Geras. A eficácia do modelo foi posteriormente testada com duas 
ocorrências de incêndio distintas, ambas com área atingida bem mapeada, porém ponto de ignição desconhecido.

\section{Material e método}

\section{Área de estudo}

O Parque Municipal da Serra de São Domingos (PMSSD), localizado no município de Poços de Caldas, em Minas Gerais, ocupa uma área de aproximadamente 367 hectares (ha), sendo aproximadamente $75 \%$ ocupado por mata atlântica, $13 \%$ por vegetação campestre, $6 \%$ por áreas de pastagem e o restante por áreas de culturas, áreas urbanizadas, minerações inativas e solo exposto (CIPRIANI et al., 2011). O PMSSD é tombado como patrimônio desde 1988, no entanto, em 2014, o Instituto Estadual de Patrimônio Histórico e Artístico (IEPHA) propôs um aumento da área do Parque, englobando uma serra adjacente, chamada Serra do Selado, para que houvesse um maior cuidado com a proteção da área (PMPC, 2014). Essa área proposta pelo IEPHA, englobando o PMSSD e a Serra do Selado, ocupa uma área de aproximadamente 1.205 ha.

Devido à área estar situada em uma altitude média entre 1.200 e 1.700 metros, a vegetação predominante na base e meio da serra é de porte arbóreo, enquanto a parte superior, suscetível a uma maior ação de correntes de ventos e maior intensidade de radiação solar, é ocupada por vegetação campestre, chamada de campos de altitude (COSTA, 2010). A área sofre anualmente com ocorrências de incêndio durante a estação seca, de junho a outubro, sendo que nos anos de 2010 a 2015, foram registradas 30 ocorrências de incêndios no PMSSD, afetando áreas que variam desde 0,1 até 15 ha (CBM, 2010-2015). A área possui espécies endêmicas de fauna e flora, e é um importante ponto turístico do municipal, possuindo um valor socioambiental inigualável.

A delimitação da área de estudo foi realizada através de um arquivo com o limite da área proposto pelo IEPHA, em formato shapefile, disponibilizados pela Prefeitura Municipal de Poços de Caldas (PMPC).

\section{Caracterização da vegetação, topografia e ocorrência de incêndio}

A fim de se caracterizar a vegetação da área de estudo, uma visita à área foi realizada, para verificar os tipos de vegetações presentes, e posteriormente, com a utilização de uma imagem de alta resolução do satélite Quick Bird, datada de 2009, foi possível dividir a ocupação da área em cinco classes: floresta, vegetação rasteira, cultivo florestal, áreas agrícolas e áreas urbanizadas. O trabalho de campo foi fundamental para o mapeamento da vegetação, pois desde a data da imagem de satélite, algumas intervenções na área foram realizadas.

A análise do relevo da área foi realizada utilizando-se um Modelo Digital de Terreno (MDT) da região de Poços de Caldas, disponibilizado pelo Instituto Nacional de Pesquisas Espaciais (INPE), a partir do qual foi possível extrair as informações referentes à elevação e declividade da área.

O Corpo de Bombeiros dispõe de relatórios de ocorrência de incêndios nos anos de 2010 a 2015 , contudo, esses são imprecisos quanto ao mapeamento da área afetada pelos incêndios, pontos de ignição, entre outras informações relevantes para a análise. Em 18 de setembro de 2017 ocorreu um incêndio na área, que perdurou por aproximadamente 3 dias, apesar da intervenção do Corpo de Bombeiros. Após contato com o Corpo de Bombeiros, e com o auxílio de um GPS, foi possível mapear a área afetada por esse incêndio e seu provável ponto de ignição. Esse incêndio foi, então, utilizado para o ajuste do modelo. Em 24 de setembro de 2017 ocorreu um outro incêndio na área, próximo ao incêndio do dia 18, sendo que este incêndio foi extinto no mesmo dia, após intervenção do Corpo de Bombeiros. Entretanto, não se sabia o possível local de ignição, sendo que houve dois possíveis locais nos quais o incêndio podia ter se iniciado.

Toda a manipulação dos arquivos georreferenciados, como shapefiles da área, imagens de

Ci. Fl., Santa Maria, v. 29, n. 4, p. 1685-1700, out./dez. 2019 
satélite, e dados topográficos, foi realizada utilizando um programa de Sistema de Informação Geográfica (SIG).

\section{Parâmetros do modelo de propagação de incêndio}

A determinação dos parâmetros do modelo consiste na simplificação da caracterização de processos complexos que envolvem um incêndio, e representados por expressões empíricas, baseando-se na física do problema (ALMEIDA, MACAU, 2011).

\section{Espaço celular e velocidade de propagação do fogo}

O espaço celular foi definido para células quadradas, de dimensão igual a $\Delta \mathrm{l}$ x $\Delta \mathrm{l}$, com $\Delta \mathrm{l}$ $=5 \mathrm{~m}$. A matriz completa para a área de estudo foi de $604 \times 1625$ células. A resolução temporal do modelo é o intervalo $\Delta t$, considerando uma iteração do modelo. A velocidade adimensional de propagação de frente de fogo $R_{a}$, e a velocidade real $R$ de propagação de frente de fogo relacionamse pela equação 1:

$$
\mathrm{R}=\mathrm{R}_{\mathrm{a}} \frac{\Delta \mathrm{l}}{\Delta \mathrm{t}}
$$

Em que: $\mathrm{R}=$ velocidade real de propagação do fogo em metros por segundos $(\mathrm{m} / \mathrm{s}) ; \mathrm{R}_{\mathrm{a}}=$ velocidade adimensional de propagação do fogo; $\Delta \mathrm{l}=$ resolução espacial $(5 \mathrm{~m}) ; \Delta \mathrm{t}=$ resolução temporal (iteração do modelo).

Nesse estudo de caso, contudo, desconhece-se a velocidade real da propagação da frente de fogo em incêndios na área, desta forma, não foi possível estimar a resolução temporal do modelo, e como explicado a seguir, o ajuste do modelo deu-se pela coincidência de áreas em incêndios reais e simulado.

Probabilidades D, B e I

Com a caracterização da vegetação da área a partir das imagens de satélite e visitas in loco, foi possível determinar os valores de densidade de vegetação $(D=1$ na presença de vegetação e $D$ $=0$, caso contrário), e com a definição de cada classe de vegetação, atribuir valores diferentes de B e I para cada classe.

Com a disponibilidade de combustível vegetal, maior é a capacidade de sustentabilidade do incêndio. Considerando que a probabilidade B é função do tipo e teor de umidade da vegetação, pode-se determinar B pela equação 2:

$$
\mathrm{B}=\mathrm{B}_{0} *\left(\frac{1}{\lambda_{\mathrm{M}}}\right)^{\mathrm{b}_{2}}
$$

Em que: $\mathrm{B}_{0}=$ probabilidade elementar de extinção do fogo em uma célula com certa classe vegetal; $\lambda_{\mathrm{M}}=$ fator de efeito da umidade; $b_{2}=$ constante empírica $\left(0 \leq b_{2} \leq 1\right)$. Na falta de dados de umidade vegetal, utilizarem-se dados da umidade relativa do ar, que assim como os dados de direção e velocidade dos ventos, foram obtidas de uma estação meteorológica localizada no centro da cidade, distante aproximadamente $2 \mathrm{~km}$ da área de estudo.

O teor de umidade do combustível vegetal influencia exponencialmente na capacidade de a vegetação inflamar e na velocidade da propagação do fogo (ALMEIDA et al., 2015). Dessa forma, o fator $\lambda_{\mathrm{M}}$ é dado pela equação 3: 


$$
\lambda_{M}=\exp \left(-b_{1} * M\right)
$$

Em que: $\mathrm{M}=$ teor de umidade da vegetação $(0 \% \leq \mathrm{M} \leq 100 \%)$; $\mathrm{b}_{1}=$ constante empírica $\left(0 \leq \mathrm{b}_{1} \leq 1\right)$.

Considerando que a probabilidade I, que trata da ignição, é influenciada por efeitos da topografia, velocidade e direção do vento e umidade da vegetação, e que esses fatores atuam de forma independente, então a determinação de I se dá pela equação 4:

$$
\mathrm{I}=\mathrm{I}_{0} * \lambda_{\mathrm{S}} * \lambda_{\mathrm{W}} * \lambda_{\mathrm{M}}
$$

Em que: $\mathrm{I}_{0}=$ probabilidade elementar de ignição do fogo para uma célula com certa classe vegetal, desprezando os efeitos do vento, topografia e umidade; $\lambda_{\mathrm{S}}=$ fator de efeito da declividade sobre a propagação; $\lambda_{\mathrm{w}}=$ fator de efeito do vento; $\lambda_{\mathrm{M}}=$ fator de efeito da umidade.

O fator $\lambda_{\mathrm{s}}$ assume a seguinte forma, pela equação 5:

$$
\lambda_{S}=\exp \left(a^{*} \theta_{S}\right)
$$

Em que: $a$ = constante empírica que ajusta o efeito da inclinação da superfície sobre a probabilidade de ignição $(0 \leq \mathrm{a} \leq 1) ; \theta_{\mathrm{s}}$ = ângulo de inclinação da superfície, calculado em função do valor de elevação $\left(\mathrm{E}_{(\mathrm{i}, \mathrm{j})}\right)$ atribuído a cada célula do modelo.

O valor de $\theta_{\mathrm{s}}$ é calculado de duas formas distintas pelas equações 6 e 7 , em função da organização da vizinha das células, se são adjacentes ou diagonais:

$$
\begin{aligned}
& \theta_{S}=\tan ^{-1}\left(\frac{E_{\left(i^{*}, j^{*}\right)^{-}} E_{(i, j)}}{\Delta l}\right), \text { se }\left(i^{*}, j^{*}\right) \text { for adjacente. } \\
& \theta_{S}=\tan ^{-1}\left(\frac{E_{\left(i^{*}, j^{*}\right)}-E_{(i, j)}}{\Delta l \sqrt{ } 2}\right), \text { se }\left(i^{*}, j^{*}\right) \text { for diagonal. }
\end{aligned}
$$

Em que: $\mathrm{E}_{(\mathrm{i}, \mathrm{j})}=$ valor de elevação atribuído a cada célula; $\mathrm{E}_{\left(\mathrm{i}^{+}, j^{i n}\right)}=$ valor de elevação atribuído à célula vizinha; $\Delta \mathrm{l}$ $=$ resolução espacial $(5 \mathrm{~m})$.

O fator $\lambda_{\mathrm{w}}$ é calculado pela equação 8:

$$
\lambda_{\mathrm{W}}=1+\mathrm{c}_{1} * f(\omega) * \mathrm{U}^{\mathrm{c}_{2}}
$$

Em que: $\mathrm{U}=$ velocidade do vento $(\mathrm{m} / \mathrm{s}) ; f(\omega)=$ fator de efeito da direção do vento sobre a probabilidade de ignição; $c_{1}$ e $c_{2}=$ constantes empíricas $\left(0 \leq c_{1} \leq 1,0 \leq c_{2} \leq 1\right)$.

O fator $f(\omega)$ pondera o efeito do vento sobre direções possíveis de propagação do fogo, como por exemplo: vento $\mathrm{N}=0^{\circ}$, vento $S=180^{\circ}$, e assim por diante. O fator $f(\omega)$ é dado pela equação 9:

$$
f(\omega)=\exp \left(c_{3} * U(\cos (\omega)-1)\right)
$$

Em que: $U$ = velocidade do vento $(\mathrm{m} / \mathrm{s}) ; \omega$ = ângulo entre a direção de propagação do fogo e a direção do vento; $\mathrm{c}_{3}=$ constante empírica $\left(0 \leq \mathrm{c}_{3} \leq 1\right)$. 
Para determinação dos valores de $\mathrm{B}_{0}$ e $\mathrm{I}_{0}$ de cada classe de vegetação, fixou-se que a propagação do incêndio ocorreria no regime dendrítico $(0<S<1)$. Dessa maneira, de acordo com a Figura 1, definiram-se valores de $\mathrm{B}_{0 \text { máx }}=0,80$ e $\mathrm{B}_{0 \text { mín }}=0,20$. Considerando velocidades de propagação em diferentes tipos de cobertura vegetal definidas em literaturas, como: McArthur (1966); Noble et al. (1980); Cheney et al. (1998); Hargrove et al. (2000); Alexandridis et al. (2008); Sullivan (2009); Almeida e Macau (2011), e definindo os limites de $\mathrm{B}_{0}$, é, então, possível estimar os valores de $\mathrm{I}_{0}$ a partir de padrões predefinidos de propagação de incêndio como aquelas da Figura 1.

\section{Constantes empíricas}

Após a definição dos valores de $\mathrm{B}_{0}$ e $\mathrm{I}_{0}$ para cada classe de vegetação, é preciso determinar os valores das constantes empíricas do modelo. Para essa finalidade, é preciso que o modelo tenha a capacidade de simular, da maneira mais próxima possível, um incêndio real, em suas condições de ocorrência. Dessa forma, procurasse uma solução ótima $\mathrm{X}$, em um espaço de busca de soluções candidatas, em um conjunto de valores prováveis das constantes empíricas, tal que $\mathrm{X}=\left(\mathrm{a}, \mathrm{b}_{1}, \mathrm{~b}_{2}, \mathrm{c}_{1}, \mathrm{c}_{2}, \mathrm{c}_{3}\right)$. Dessa forma, foi realizado um comparativo entre as áreas afetadas dos incêndios, real e simulado, tal qual a equação 10:

$$
f(x)=1-\frac{A\left(A_{R} \cap A_{S}\right)}{A\left(A_{R} \cup A_{S}\right)}
$$

Em que: $A\left(A_{R} \cap A_{S}\right)=a$ área da intersecção entre as áreas dos incêndios real $\left(A_{R}\right)$ e o simulado $\left(A_{S}\right) ; A\left(A_{R} U A_{S}\right)$ $=\mathrm{a}$ área da união entre as áreas dos incêndios real $\left(\mathrm{A}_{\mathrm{R}}\right)$ e o simulado $\left(\mathrm{A}_{\mathrm{S}}\right)$.

Caso a simulação reproduza com exatidão a área do incêndio real, então a função é igual a 0 . Qualquer outro valor resultará em $0 \leq f(x) \leq 1$, pois há intersecção ao menos da célula de ignição. Portanto, o interesse do ajuste é minimizar a função $f(x)$. Para o ajuste das constantes, utilizou-se um algoritmo de vagalumes (YANG, 2008), o qual de forma geral explica que emissões luminosas de um vagalume atua como atrativo para outros vagalumes. De maneira simplificada, o algoritmo se embasa no comportamento de vagalumes (possíveis soluções) inseridos em um espaço de busca, em que, para cada vagalume, se atribui uma posição nesse espaço.

O algoritmo é regido por três regras: os vagalumes vagam no espaço de busca guiados por um mecanismo de atração; essa atratividade é proporcional à emissão luminosa dos vagalumes e diminui em relação à distância entre eles; a intensidade luminosa emitida por um vagalume é calculada em função de sua posição em relação à função $f(x)$, quanto melhor considerada, maior luminosidade emitida.

Dessa forma, um vagalume $i$ propõe uma solução candidata para o problema, $x_{i}^{t}=\left(x^{1}(1)\right.$, $\left.\mathrm{x}^{2}(2), \ldots, \mathrm{x}_{\mathrm{i}}(\mathrm{d})\right)$, inserida em um espaço de busca $\mathrm{S}$ de dimensão $\mathrm{d}$, e move-se em seu interior em passos discretos de tempo t. O algoritmo é definido por duas características: como ocorre a variação de luz percebida pelos vagalumes menos brilhantes e como ocorre a atração entre eles. No espaço de busca, a intensidade de luz percebida por um vagalume $i$ (menos brilhante e a ser atraído) que é emitida por um vagalume $j$ (mais brilhante), decresce em função da distância entre eles. Assim, um fator de atratividade $\beta$ é definido pela equação 11:

$$
\beta\left(r_{(i, j)}\right)=\beta_{0} e^{-\gamma r_{i, j}^{m}}
$$

Em que: $r_{i, j}=$ distância entre os vagalumes; $\beta_{0}=$ parâmetro que estima a atratividade para uma distância $r_{i, j}=$ $0 ; \gamma=$ parâmetro de absortividade; $\mathrm{m}$ = parâmetro que controla a influência da distância sobre a atratividade. 
O movimento do vagalume sendo atraído (i) em direção ao vagalume brilhante (j) é dado pela equação 12:

$$
x_{i}^{t+1}=x_{i}^{t}+\beta\left(r_{i, j}\right) *\left(x_{j}^{t}-x_{i}^{t}\right)+\alpha \epsilon_{i}
$$

Em que: $\beta\left(\mathrm{r}_{(\mathrm{i}, \mathrm{j}}\right)=$ atratividade; $\alpha \epsilon_{\mathrm{i}}=$ aleatoriedade; $\alpha$ = parâmetro de aleatoriedade; $\epsilon_{\mathrm{i}}=$ vetor $\mathrm{d}$-dimensional de números aleatórios.

Considerando $\beta_{0}=1$, pode-se determinar que a atratividade é máxima a uma distância nula. Assim, o desempenho do algoritmo se condiciona às determinações dos parâmetros $\gamma \mathrm{e}$ $\alpha$, em que o primeiro designa o decrescimento da atratividade no espaço de busca, enquanto o segundo designa a aleatoriedade do movimento do vagalume. O parâmetro $\alpha$ assume um valor inicial $\left(\alpha_{\mathrm{i}}\right)$ e decresce ao longo das iterações do algoritmo, até um valor final $\left(\alpha_{\mathrm{f}}\right)$, conforme a equação 13:

$$
\alpha_{t+1}=\alpha_{t}\left(\frac{\alpha_{f}}{\alpha_{i}}\right)^{1 /\left(N_{i t e r}-1\right)}
$$

$$
\text { Em que: } \alpha_{t-1}=\alpha_{i} ; t=2,3, \ldots, N_{i t e r}
$$

Durante a execução do algoritmo, cada possível solução (vagalume) ocupa uma posição no espaço, procurando representar uma solução possível para as constantes, e seu brilho é proporcional à avaliação da solução da função $f(x)$. A cada iteração do algoritmo, são atribuídas novas posições para os vagalumes, e o brilho é recalculado, ao decorrer das iterações, os vagalumes se juntam em torno dos melhores valores encontrados para a função $f(x)$.

Com isso, foi definido que seriam realizadas 10 tentativas do algoritmo, utilizando um número de 20 vagalumes, e a cada tentativa, seriam realizadas 10 simulações, obtendo assim um valor médio para a função $f(x)$. Ao final das 10 simulações para cada número de tentativa, seriam feitas 10 interações, para adequar o conjunto de parâmetros dos vagalumes, obtendo valores ótimos para cada constante, e reiniciando o ciclo, sempre otimizando a função $f(x)$. Esses números foram definidos em função das restrições de hardware computacional e tempo disponível, pois nas configurações disponíveis, foi estimado uma duração de 2 meses para as simulações.

\section{Resultados e discussão}

Verificou-se que a classe denominada "floresta" ocupa a maior parte da área de estudo, aproximadamente $55 \%$, entretanto, conforme verificado pelas informações fornecidas pelo Corpo de Bombeiros, é onde ocorre o menor número de incêndios. Por outro lado, a classe denominada "vegetação rasteira" ocupa, aproximadamente $34 \%$ da área, é onde ocorre a maior parte dos incêndios na área, quase três vezes a quantidade de incêndios na classe floresta. A área de cultivo florestal ocupa 3\%, enquanto as áreas urbanizadas e de plantações ocupam, juntas, $7 \%$. A cobertura vegetal da área pode ser vista na Figura 2. 
Figura 2 - Mapa de cobertura vegetal e ocupação da área de estudo.

Figure 2 - Vegetation cover map and occupation of the study area.

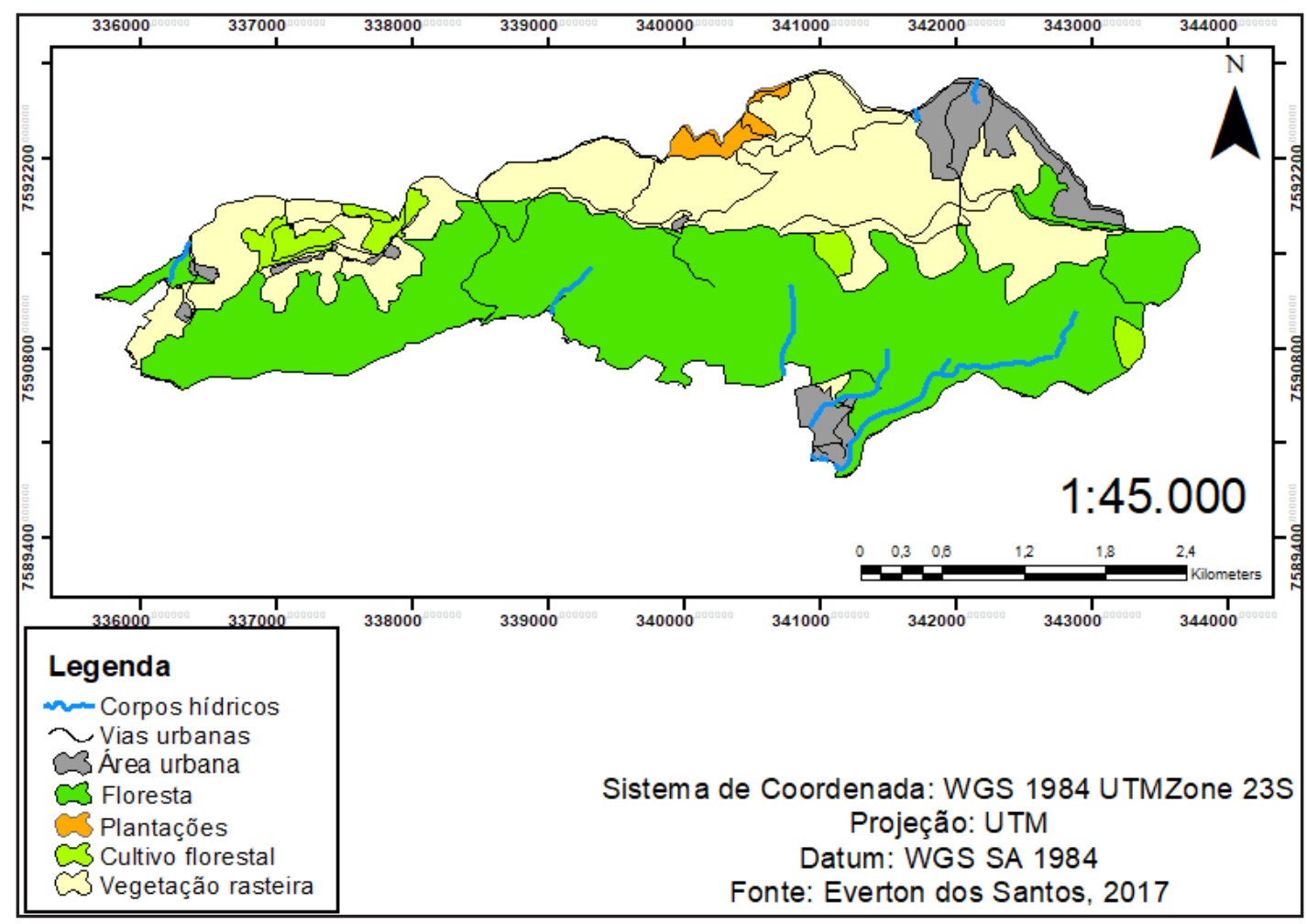

Fonte: Autores (2017)

Source: Authors (2017)

O MDT utilizado para caracterização da topografia da área apresentou valores de altitude entre $1.200 \mathrm{~m}$ e $1.630 \mathrm{~m}$, e a declividade predominante é a da classe "forte ondulado" variando entre 20 e 45\%. Algumas áreas também apresentam classes de declividade "montanhoso" e "escarpado", variando de valores acima de 45 até $75 \%$. A Figura 3 mostra os resultados para a elevação na área de estudo.

Após visita à área de estudo a fim de se mapearem os incêndios ocorridos em 18 e 24 de setembro de 2017, verificou-se que estes atingiram áreas de, respectivamente, 18,9 ha e 18,6 ha. O provável ponto de ignição do incêndio do dia 18 encontrava-se próximo a uma estrada de acesso à área de visitação do mirante do parque, enquanto havia duas suspeitas de possíveis pontos de ignição para o incêndio do dia 24 . Verificou-se que ambos os incêndios atingiram apenas a vegetação rasteira da área, não adentrando para as áreas de floresta e cultivo florestal, e as trilhas e estradas presentes na área funcionaram como aceiro, não permitindo que os incêndios se propagassem para outras áreas. Os incêndios se comportaram conforme previsto na teoria, propagando-se no sentido morro acima, e morro abaixo quando a velocidade e direção dos ventos foram favoráveis. As áreas atingidas pelos incêndios, assim como os possíveis pontos de ignição, podem ser verificadas na Figura 4. 
Figura 3 - Mapa de elevação da área de estudo.

Figure 3 - Elevation map of the study area.

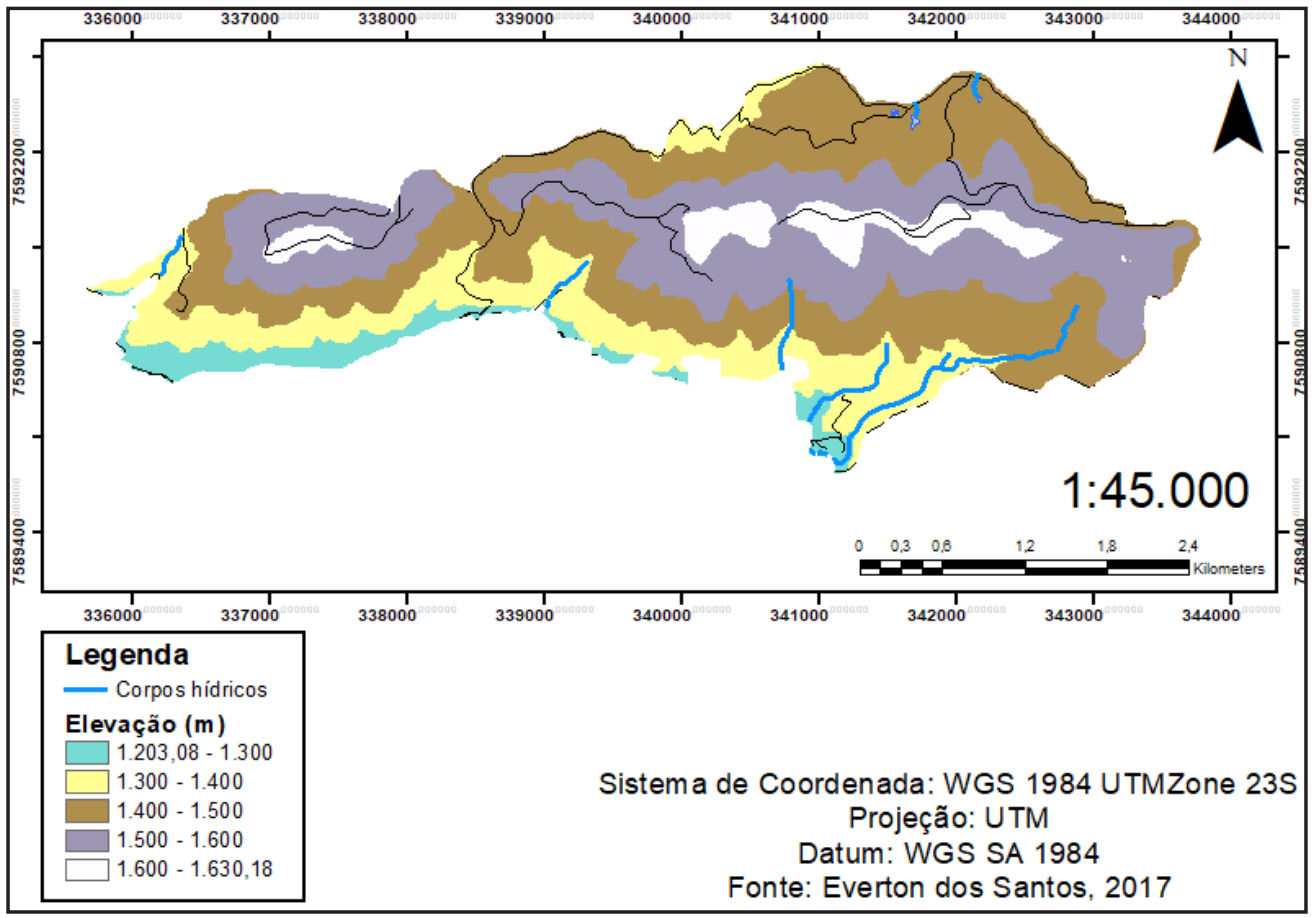

Fonte: Autores (2017)

Source: Authors (2017)

Figura 4 - Áreas afetadas por incêndios ocorridos em 18 e 24 de setembro de 2017.

Figure 4-Areas affected by fires that occurred on September 18 and 24, 2017.

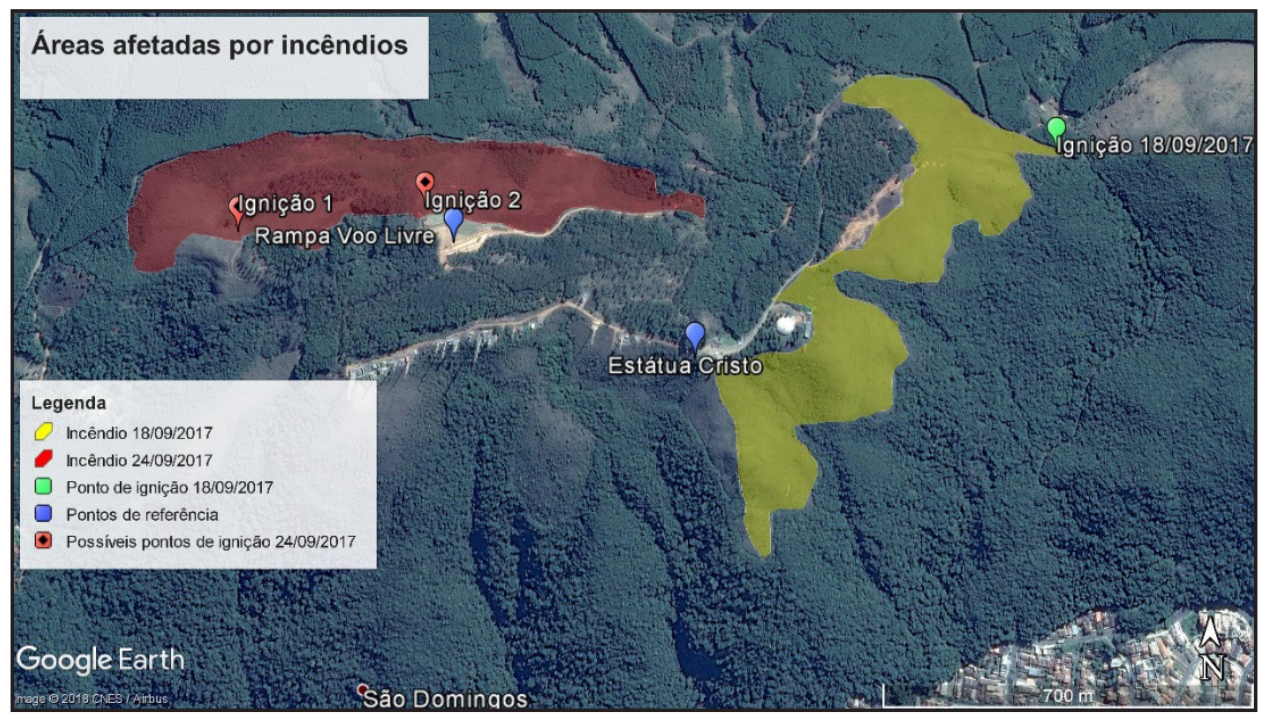

Fonte: Google Earth (2018)

Source: Google Earth (2018) 
Assumiu-se que as áreas urbanas e de plantações não seriam consideradas nas simulações do incêndio, e definiu-se que a velocidade de propagação da frente do fogo nas áreas de cultivo florestal seria de $70 \%$ e das áreas de floresta seria de $20 \%$ em relação à velocidade de propagação do fogo nas áreas de vegetação rasteira; esses valores foram estimados a partir da análise da velocidade de propagação dos incêndios $\left(\mathrm{em} \mathrm{m}^{2} / \mathrm{s}\right.$ ) relatados de 2010 a 2015 . Com isso, assumiu-se que a floresta teria $\mathrm{B}_{0}=0,8$ (máximo) e que a vegetação rasteira assumiria $\mathrm{B}_{0}=0,2$ (mínimo), a área de cultivo florestal teria $\mathrm{B}_{0}=0,4$. Atribuindo valores de velocidade máxima de propagação para a vegetação rasteira, pode-se, em comparativo com a Figura 1 , atribuir o valor de $\mathrm{I}_{0}$ máximo a essa classe de vegetação, de 0,325. Partindo das relações de velocidade atribuídas anteriormente, pode-se chegar aos valores de $\mathrm{B}_{0}$ e $\mathrm{I}_{0}$ para as outras classes de vegetação, conforme Tabela 1.

Tabela 1 - Valores atribuídos para as probabilidades $I_{0}$ e $B_{0}$ para cada classe de vegetação.

Table 1 - Assigned values for the probabilities $\mathrm{I}_{0}$ and $\mathrm{B}_{0}$ for each class of vegetation.

\begin{tabular}{cccc}
\hline & Floresta & Vegetação rasteira & Cultivo florestal \\
\hline $\mathbf{I}_{\mathbf{0}}$ & 0,05 & 0,325 & 0,10 \\
$\mathbf{B}_{\mathbf{0}}$ & 0,80 & 0,20 & 0,40 \\
\hline
\end{tabular}

O incêndio utilizado para ajuste do modelo foi o incêndio ocorrido no dia 18 de setembro de 2017, as condições meteorológicas do dia do início do incêndio e os dias seguintes em que ele ocorreu foram adquiridas de uma estação meteorológicas situada no centro do município de Poços de Caldas. As condições meteorológicas para o dia 24 de setembro também foram adquiridas da mesma estação, e essas informações podem ser verificadas na Tabela 2. Vale ressaltar que a estação meteorológica não está situada nos limites do parque, estando distante aproximadamente $2 \mathrm{~km}$ da área de estudo.

Tabela 2 - Condições meteorológicas durante as ocorrências de incêndios iniciados em 18 e 24 de setembro de 2017.

Table 2 - Meteorological conditions during the occurrence of fires started on September 18th and $24^{\text {th }}, 2017$.

\begin{tabular}{|c|c|c|c|c|c|c|}
\hline \multirow[t]{2}{*}{ Data } & \multicolumn{3}{|c|}{ Umidade (\%) } & \multicolumn{2}{|c|}{$\begin{array}{c}\text { Velocidade do } \\
\text { vento }(\mathbf{k m} / \mathbf{h})\end{array}$} & \multirow[t]{2}{*}{ Direção do vento } \\
\hline & Máx & Mín & Média & Máx & Média & \\
\hline 18/09/2017 & 60 & 24 & 41 & 10,0 & 4,0 & $\mathrm{NE}-45^{\circ}$ \\
\hline $19 / 09 / 2017$ & 55 & 19 & 38 & 9,0 & 4,0 & ESE - 112,5은 \\
\hline 20/09/2017 & 47 & 32 & 42 & 12,0 & 6,0 & $E-90^{\circ}$ \\
\hline 24/09/2017 & 60 & 28 & 44 & 16,0 & 4,0 & $\mathrm{NE}-45^{\circ}$ \\
\hline
\end{tabular}

Em que: $\mathrm{NE}=$ nordeste; $\mathrm{ESE}$ = leste-sudeste; $\mathrm{E}$ = leste.

No ajuste das constantes empíricas, consideraram-se os valores médios para umidade e velocidade do vento no dia 18 de setembro, data do início do incêndio. Ao final do processo de otimização, os valores encontrados para as constantes estão apresentados na Tabela 3 : 


\section{Tabela 3 - Valores encontrados para as constantes do modelo.}

Table 3 - Values found for the model constants.

\begin{tabular}{cccccc}
\hline $\begin{array}{c}\text { Constante } \\
\text { empírica }\end{array}$ & $\begin{array}{c}\text { Valores } \\
\text { ajustados }\end{array}$ & $\begin{array}{c}\text { Valores estimados por } \\
\text { Almeida et al. (2015) }\end{array}$ & $\begin{array}{c}\text { Limite } \\
\text { inferior }\end{array}$ & $\begin{array}{c}\text { Limite } \\
\text { superior }\end{array}$ & Referência \\
\hline $\mathbf{a}$ & 0,0645 & $0,0645 \pm 0,0103$ & 0,040 & 0,080 & $\begin{array}{c}\text { (MCARTHUR, 1966; } \\
\text { NOBLE et al., 1980) }\end{array}$ \\
$\mathbf{b}_{1}$ & 0,0783 & $0,3140 \pm 0,0094$ & 0,000 & 1,000 & (ALMEIDA, 2015) \\
$\mathbf{b}_{2}$ & 0,0233 & $0,0061 \pm 0,0015$ & 0,001 & 0,200 & (CHENEY et al., 1998) \\
$\mathbf{c}_{1}$ & 0,1617 & $0,1852 \pm 0,0191$ & 0,000 & 1,000 & (ALMEIDA, 2012) \\
$\mathbf{c}_{2}$ & 0,8304 & $1,0159 \pm 0,0881$ & 0,800 & 1,200 & (SULLIVAN, 2009) \\
$\mathbf{c}_{3}$ & 0,1303 & $0,2102 \pm 0,0271$ & 0,100 & 0,300 & (ALEXANDRIDIS et al., \\
\hline
\end{tabular}

A comparação com os valores encontrados por Almeida (2012) em seu estudo no Cerrado brasileiro, revela que as constantes relacionadas aos efeitos da topografia e do vento são próximas, enquanto as constantes relacionadas ao efeito da umidade são diferentes em algumas ordens de grandeza. Acredita-se que esse resultado ocorreu por causa das informações meteorológicas utilizadas, pois não há uma estação de coleta de dados na área de estudo, e que os efeitos do vento e da umidade são diferentes na região serrana quando comparados com as condições encontradas em uma área urbanizada, por exemplo. A correspondência entre as áreas que compreendem o incêndio real e o simulado foi de 55\%, um valor considerado baixo, para esse tipo de modelo. Entretanto, quando realizadas simulações com condições de umidade mínima e velocidade máxima do vento, a correspondência entre as áreas aumentou significativamente.

Definidos os valores das constantes empíricas, duas simulações foram realizadas para o incêndio do dia 18 de setembro e duas para o incêndio do dia 24 . Na simulação 1, utilizaramse os dados meteorológicos do dia 18 , enquanto na simulação 2 , utilizaram-se os dados do dia 19 de setembro. Nas simulações 3 e 4, foram utilizados os dados meteorológicos do dia 24 de setembro, alterando o ponto de ignição para cada uma das simulações. Para cada simulação, foram realizadas 10 repetições, a fim de se obter um valor médio para a função $f(x)$ e um valor mínimo, que seria a simulação mais representativa possível para cada uma das condições. A Tabela 4 apresenta um resumo das condições de cada simulação.

Tabela 4 - Resumo das condições utilizadas em cada simulação.

Table 4 - Summary of the conditions used in each simulation.

\begin{tabular}{lcccc}
\hline & \multicolumn{4}{c}{ Simulação } \\
\hline Parâmetros & 1 & 2 & 3 & 4 \\
Umidade mínima & $24 \%$ & $19 \%$ & $28 \%$ & $28 \%$ \\
$\begin{array}{l}\text { Velocidade máxima } \\
\text { do vento }\end{array}$ & $10,0 \mathrm{~km} / \mathrm{h}$ & $9,0 \mathrm{~km} / \mathrm{h}$ & $16,0 \mathrm{~km} / \mathrm{h}$ & $16 \mathrm{~km} / \mathrm{h}$ \\
$\begin{array}{l}\text { Direção do vento } \\
\text { Ponto de ignição }\end{array}$ & $\mathrm{NE}-45 \stackrel{\mathrm{o}}{ }$ & $\mathrm{ESE}-112,5 \mathrm{o}$ & $\mathrm{NE}-45^{\mathrm{o}}$ & $\mathrm{NE}-45$ o \\
\hline
\end{tabular}


Ao término das dez repetições para cada uma das simulações, obteve-se um valor médio para $f(\mathrm{x})$, e foram selecionadas as simulações que obtiveram $f(\mathrm{x})$ mínimo, para efeito de comparação visual com as áreas afetadas durante o incêndio real. A Tabela 5 apresenta os valores obtidos durante as simulações e a Figura 5 e a Figura 6 mostram um comparativo visual entre a área afetada pelos incêndios reais e as áreas afetadas pelos incêndios simulados com os menores valores de $f(x)$.

Tabela 5 - Valores de $f(\mathbf{x})$ médio e mínimo para cada simulação.

Table 5 - Mean and minimum values of $\mathrm{f}(\mathrm{x})$ for each simulation.

\begin{tabular}{cccc}
\hline & $f(\mathbf{x})$ médio & $f(\mathbf{x})$ mínimo & $f(\mathbf{x})$ máximo \\
\hline Simulação 1 & 0,66 & 0,52 & 0,73 \\
Simulação 2 & 0,55 & 0,43 & 0,66 \\
Simulação 3 & 0,55 & 0,43 & 0,61 \\
Simulação 4 & 0,73 & 0,62 & 0,85 \\
\hline
\end{tabular}

Notou-se que a simulação 2 obteve resultados melhores que a simulação 1 , que pode ser explicado pela direção do vento considerada nessa simulação. O incêndio iniciou-se no dia 18 durante a noite, e durou por aproximadamente três dias, demonstrando uma certa sustentabilidade da vegetação para essa situação. Com a utilização dos dados meteorológicos do dia 18, a direção do vento considerada não favorece a propagação do incêndio no sentido preferencial (morro acima), porém, a direção do vento do dia 19 muda esse contexto, o que pode ser usado para justificar a duração prolongada do incêndio, apesar do combate realizado pelo Corpo de Bombeiros

Figura 5 - Comparativo entre incêndio real e simulações. (a) incêndio real 18/09/2017; (b) simulação $1-f(\mathbf{x})$ mínimo = 0,52; (c) simulação $2-f(\mathbf{x})$ mínimo = 0,43.

Figure 5 - Comparison between actual fire and simulations. (a) real fire 09/18/2017; (b) simulation $1-\mathrm{f}(\mathrm{x})$ minimum $=0.52 ;(\mathrm{c})$ simulation $2-\mathrm{f}(\mathrm{x})$ minimum $=0.43$.

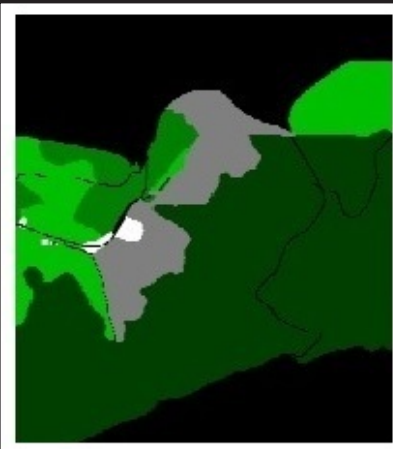

(a)

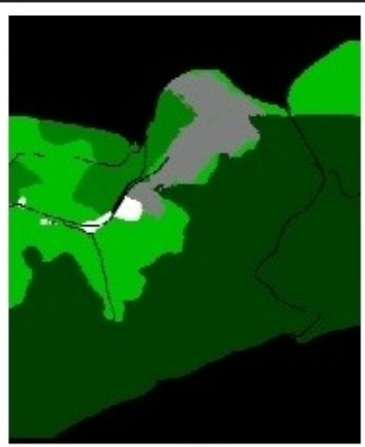

(b)

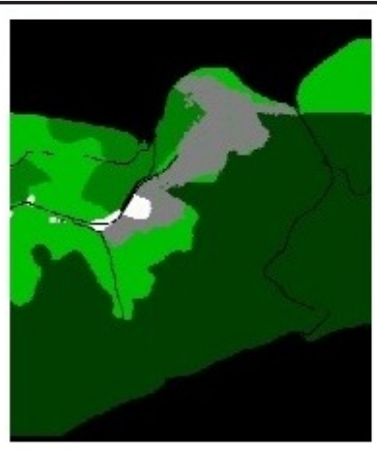

(c)

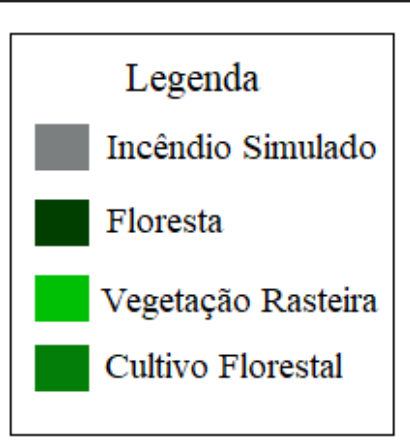

Floresta

Vegetação Rasteira

Cultivo Florestal

Fonte: Autores (2017)

Source: Authors (2017) 
Pode-se observar também, que, em média, a simulação 1 conseguiu representar $34 \%$ da área real do incêndio, enquanto a melhor simulação para essa condição conseguiu representar $48 \%$. A simulação 2 conseguiu representar, em média, $45 \%$ da área real, enquanto sua melhor repetição conseguiu representar $57 \%$. Os resultados, provavelmente, seriam melhores caso houvesse a possibilidade de levantamento de uma série histórica de velocidade e direção do vento para a área de estudo.

Outro fator que poderia melhorar a representatividade do modelo seria conhecer exatamente a velocidade de propagação do fogo na área de estudo, pois dessa maneira seria possível saber o valor da constante de tempo de propagação do fogo a cada iteração do modelo, ocasionando resultados melhores para as simulações do modelo. Para isso, seria necessário monitorar um incêndio sem intervenções, naturais ou não, ou realizar um experimento de queima controlada em uma área similar às condições encontradas na área de estudo. Assim, caso a resolução temporal do modelo possa ser estimada, o modelo pode ser ajustado para que as condições meteorológicas variem ao longo da iteração do modelo a partir dos dados da série histórica.

Figura 6 - Comparativo entre incêndio real e simulações. (d) incêndio real 24/09/2017; (e) simulação 3 - $f(\mathbf{x})$ mínimo = 0,43; (f) simulação 4 - $f(\mathbf{x})$ mínimo = 0,62.

Figure 6 - Comparison between the actual fire and simulations. (d) real fire 09/24/2017; (e) simulation $3-f(\mathrm{x})$ minimum $=0.43$; (f) simulation $4-f(\mathrm{x})$ minimum $=0.62$.

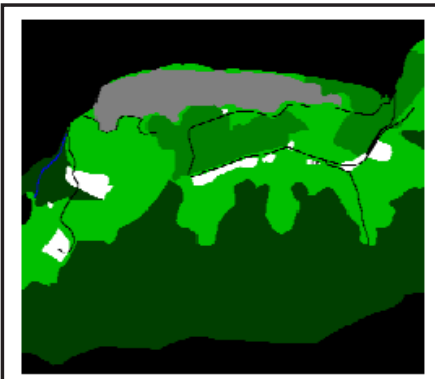

(d)

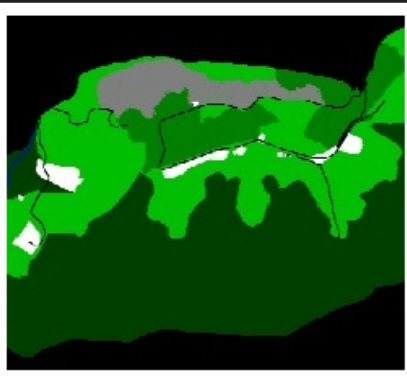

(e)

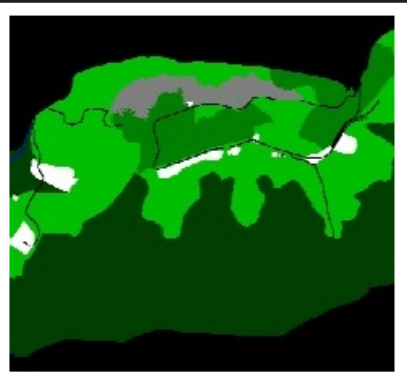

(f)

Fonte: Autores (2017)

Source: Authors (2017)

Nas simulações 3 e 4 fica evidente a necessidade de precisão com relação ao ponto de ignição, pois, para as mesmas condições meteorológicas, a simulação 3, que contava com o ponto de ignição mais à esquerda, se beneficiou da direção do vento, e conseguiu representar $57 \%$ da área do incêndio real, enquanto a simulação 4 , com ponto de ignição mais à direita, conseguiu representar $37 \%$ da área real.

\section{Conclusão}

O modelo de propagação de incêndio analisado obteve um desempenho mediano, uma vez que as melhores simulações conseguiram representar 48, 57, 57 e 37\% de áreas afetadas por incêndios reais, para as simulações $1,2,3$ e 4 , respectivamente.

Apesar de não conseguir representar em sua totalidade uma situação de incêndio real, o modelo mostrou alguns resultados esperados em relação às literaturas e situações reais observadas na área. A maioria dos incêndios ocorre na vegetação rasteira, e as escolhas para 
as probabilidades elementares $\mathrm{I}_{0}$ e $\mathrm{B}_{0}$ se mostraram condizentes, nesse ponto, pois os incêndios simulados não se propagam com facilidade para as áreas de floresta e cultivo florestal.

Observou-se que em pequenas áreas, o modelo tem forte dependência dos efeitos de velocidade e direção dos ventos, bem como do valor utilizado para umidade do ar. Existe a necessidade de obtenção de dados meteorológicos mais completos e representativos para a área de estudo, pois dessa maneira seria possível realizar um ajuste do modelo mais eficaz. Também há a necessidade de se conhecer, com a maior precisão possível, os pontos de ignição para os incêndios reais.

\section{Agradecimentos}

Agradecemos aos professores Paulo Henrique Junker Bretanha Menezes e Rodolfo Maduro Almeida pelo auxílio prestado no desenvolvimento desse trabalho e à CAPES pelo financiamento do projeto.

\section{Referências}

ACHTEMEIER, G. L. Field validation of a free-agent cellular automata model of fire spread with fire-atmosphere coupling. International Journal of Wildland Fire, EUA, v. 22, p. 148-156, 2013.

ADOU, J. K.; BROU, A. D. V.; PORTERIE, B. Modeling wildland fire propagation using a semiphysical network model. Cases Studies in Fire Safety, [S.1.], v. 4, p. 11-18, 2015.

ALEXANDRIDIS, A. et al. A cellular automata model for forest fire spread prediction: The case of the wildfire that swept through spetses island. In 1990. Applied Mathematics and Computation, [S.1.], v. 204, n. 1, p. 191-201, 2008.

ALMEIDA, R. M.; MACAU, E. E. N. Stochastic cellular automata model for wildland fire spread dynamics. Jornal of Physics: Conference Series, [S.1.], v. 285, n. 1, 2011.

ALMEIDA, R. M. et al. Autômatos celulares probabilísticos aplicados à modelagem da propagação de incêndios de vegetação. Proceeding series of the Brazilian Society of Applied and Computational Mathematics, São Carlos, v. 3, n. 1, 2015.

ANDRE, J. C. S.; VIEGAS, D. X. Modelos de propagação de fogos florestais: Estado da arte para utilizadores (parte I: Introdução e modelos locais). Silva Lusitana, Lisboa, Portugal, v. 9, n. 2, p. 237-264, 2001.

CHENEY, N. P.; GOULD, J. S.; CATCHPOLE, W. R. Prediction of fire spread in grasslands. International Journal of Wildland Fire, EUA, v. 8, n. 1, p. 1-13, 1998.

CIPRIANI, H. N. et al. Fire risk map for the Serra de São Domingos Municipal Park, Poços de Caldas, MG. CERNE, Lavras, v. 17, n. 1, p. 77-83, 2011.

CORPO DE BOMBEIROS MILITAR (CBM) - 1a Companhia Independente De Poços de Caldas - 6 Comando Operacional Do Estado de Minas Gerais. Relatórios de Eventos de Defesa Civil. 2010-2015

COSTA, M. P. Ecologia da vegetação arbórea na Serra de São Domingos, Poços de Caldas (MG). 2010 Dissertação (mestrado) - Universidade Federal de Lavras (UFLA), 2010.

D’AMBROSIO, D. et al. A model for the simulation of forest fire dynamics using cellular automata. In: iEMS 2006, Summit on Environmental Modelling and Software, Vermont, EUA, 2006.

HARGROVE, W. W. et al. Simulating fire patterns in heterogeneous landscapes. Ecological Modelling, [S.1.], v. 135, p. 243-263, 2000. 
INSTITUTO NACIONAL DE PESQUISAS ESPACIAIS (INPE). Banco de Dados Geomorfométricos do Brasil. Disponível em: http://www.dsr.inpe.br/topodata/.

IUDIN, D. I.; SERGEYEV, Ya. D.; HAYAKAWA, M. Infinity computations in cellular automaton forest-fire model. Communications in Nonlinear Science and Numerical Simulation, [S.l.], v. 20, n. 3, p. 861-870, 2015.

LI, C.; LI, J.; HU, L.; HOU, D.; Visualization and simulation model of underground mine fire disaster based on Cellular Automata. Applied Mathematical Modelling, [s.I.], v. 39, n. 15, p. 4351-4364, 2015.

MCARTHUR, A. G. Weather and grassland fire behaviour. Forestry and Timber Bureau, Department of National Development, Commonwealth of Australia, 1966.

NOBLE, I. R.; GILL, A. M.; BARY, G. A. V. McArthur's fire-danger meters expressed as equations. Australian Journal of Ecology, Austrália, v. 5, n. 2, p. 201-203, 1980.

PASTOR, E. et al. Mathematical models and calculation systems for the study of wildland fire behaviour. Progress in Energy and Combustion Science, [s.I.], v. 29, n. 2, p. 139-153, 2003.

PREFEITURA MUNICIPAL DE POÇOS DE CALDAS (PMPC). Conselho de Defesa do Patrimônio Histórico, Artístico, Cultural e Turístico de Poços de Caldas (CONDEPHACT-PC). Ata da 94 reunião ordinária do Conselho Deliberativo Municipal de Defesa do Patrimônio Histórico, Artístico, Cultural e Turístico do Município de Poços de Caldas, 2014. Disponível em: http://www.pocosdecaldas.mg.gov.br/site/?page_id=23501. Acesso em: janeiro de 2018.

PYNE, J. S.; ANDREWS, P. L.; LAVEN, R. D. Introduction to wildland fire. 2 ed. New York, EUA, John Wiley \& Sons, 1996.

SULLIVAN, A. L. Wildland surface fire spread modelling, 1990-2007. 2: Empirical and quaseempirical models. International Journal of Wildland Fire, EUA, v. 18, n. 4, p. 387-403, 2009.

YANG, X. S. Nature-Inspired Meteheuristic Algorithms. Frome, UK: Luniver Press, 2008. 